\title{
A (INSISTENTE) PROBLEMATIZAÇÃO DO ESTRUTURAL VERSUS CONTEXTUAL PARA O TRATAMENTO DA SIGNIFICÂNCIA: UMA ANÁLISE DO 'PARADOXO SEMÂNTICO’ À LUZ DA TEORIA DOS BLOCOS SEMÂNTICOS
}

\author{
Julio Cesar MACHADO*
}

- RESUMO: O presente artigo elege a seguinte questão fulcral: como operar o confronto ou aliança entre estrutura da linguagem e seu funcionamento para refletir a significância nesta/desta relação? Para apreendermos esta problemática, mobilizaremos dois objetivos, que são questões que inquietam o semanticista de qualquer filiação: como estabilizar, em Linguística, aspectos teóricos diante de (a) estruturas fora do uso, ambiguamente semânticas, e também diante de (b) estruturas que permitem vários usos, e por isso apresentam/produzem vários sentidos? Para analisar tais objetivos, valer-nos-emos de uma definição de "paradoxo" enquanto corpus, que nos permitirá operar, de fato, nosso objeto de estudo: o paradoxo semântico, neonoção que observa contrários interdependentes, e que tomaremos enquanto noção técnica no interior da Teoria dos Blocos Semânticos, de Carel e Ducrot, filiação teórica basilar desta pesquisa. Nossa hipótese é confirmada pelos resultados obtidos: qualquer que seja o procedimento estratégico que se opere ou que se nomeie, a significação estrutural é ponto de passagem e de retorno em análise semântica, o que nos leva a concluir que, se não se pode entender o movimento sem a ideia de inércia, não se pode trabalhar o sentido enunciativo sem a significação estrutural. Tal condição parece ser imperativa em Semântica.

- PALAVRAS-CHAVE: Paradoxo semântico. Argumentação estrutural. Argumentação contextual.

\section{Introdução}

A Semântica Argumentativa ocupa lugar significativo nos trabalhos mundiais em Semântica, Argumentação e Enunciação, dentre outros.

Em 1992 temos um marco singular de reformulação do quadro teórico deste saber: a ideia base de investigar a argumentação por vias dos blocos semânticos, sugerida por Marion Carel: dá-se início à Teoria dos Blocos Semânticos (TBS) nos estudos estruturais enunciativos. A TBS, porém, não se trata de outra teoria que rompe com a anterior.

\footnotetext{
Universidade do Estado de Minas Gerais (UEMG), Faculdade de Educação, Minas Gerais, Brasil. julio.semantica@ gmail.com. ORCID: 0000-0003-0364-3370
} 
Ao longo dos trabalhos em Semântica Argumentativa, a diversidade de nomenclaturas não significa várias teorias autônomas: Argumentação na Língua, escalas absolutas, Teoria dos Topoï, Teoria Polifônica da Enunciação, Teoria Argumentativa da Polifonia e Teoria dos Blocos Semânticos são modos distintos de trabalhar a mesma proposta da argumentação na língua através de procedimentos específicos utilizados por cada uma, que foram nomeados inicialmente, de modo totalizante, Semântica Argumentativa (CAREL; DUCROT, 2005), e hoje leva apenas o nome de TBS. Assim, estes vários nomes são diferentes meios de se fazer uma única Semântica por vias argumentativas, através de dispositivos teóricos que se complementam: o leitor atento da TBS perceberá que os vários engendramentos para trabalhar a argumentação na língua, ao longo dos anos, instigam uma relação não de separação, mas de complementação (CAREL, 2012). São arcabouços para investigar a língua em enunciação por cuidados estruturais, com preocupações desiguais. O que temos é senão uma única teoria, sempre em evolução desde sua criação, e agora aprofundada de modo radicalizado na sua fase atual, a TBS.

E ainda: permanece sempre, então, o mesmo interesse inicial nos objetos língua, enunciação, significação e sentido, investigados pelo prisma da argumentação na língua.

Este "vários" que entendemos como um "todo", isto é, o eco da discussão de décadas da teoria desenvolvida por Anscombre e Ducrot (1983), é agora ricamente retomado, reformulado, aprofundado e amadurecido na atualidade da TBS, como veremos. A TBS firmou-se enquanto hipótese semântica de sucesso ao pretender investigar a língua e o discurso por vias argumentativas, fiel à proposta ducrotiana de uma "concepção estrutural da enunciação" (DUCROT, 1987, p.83).

O propósito deste artigo é justamente refletir sobre o modo como o sentido/ significação se porta na língua nas duas dimensões estrutura e enunciação, polemizadas, contrastadas, aliadas ou isoladas em várias filiações da Linguística, e aqui tomada de modo particular e argumentativo, como veremos, a partir de certas atualizações da TBS, sobremaneira nos últimos dez anos.

A consequência desse rigor de atualização tem sido o interessante norte que tal atualização dá às pesquisas sobre Argumentação e Semântica, ao conseguir relacionar posturas estruturalistas e enunciativas às preocupações e interesses modernos e/ou de interesses contemporâneos, próprios das vertentes da Linguística ou de outros tipos de vertentes, como os estudos sobre o paradoxo, por exemplo. Tal abertura, no mínimo, faz ressignificar o que se entende por Estruturalismo na atualidade. Dentre outros sentidos produzidos.

\section{O valor da frase ou do enunciado: a relação aspecto/encadeamento}

Há uma singularidade metodológica que particulariza toda a TBS: a argumentação, noção pela qual a TBS investiga a significação e o sentido, será tecnicamente tratada sempre pelo valor (da frase ou do enunciado). Este valor preserva o propósito da TBS de observar nas frases as marcas relativas à sua construção, e no enunciado as marcas 
relativas à sua enunciação (DUCROT, 1987). E o fará pela dinâmica de duas noções: "Os dois valores que a TBS associará a um enunciado serão o aspecto que ele exprime e o encadeamento que lhe parafraseia." (CAREL, 2011, p.160, tradução nossa, grifo nosso) ${ }^{1}$.

Ao investigar o valor (aspecto e encadeamento) de uma palavra, por exemplo "prudente", Carel explica que tal palavra exprime o aspecto [PERIGO PORTANTO PRECAUÇÃO], e que esse aspecto evoca um encadeamento que o concretiza, que poderia ser: "Pedro foi prudente". Como bem explica a linguista ${ }^{2}$ :

O sentido de Pedro foi prudente é duplo. De uma parte, o enunciado exprime o aspecto argumentativo PERIGO PORTANTO PRECAUÇÃO, e de outra parte ele evoca o encadeamento 'era perigoso portanto Pedro tomou precauções' [...] O encadeamento evocado faz do enunciado uma formulação concreta do aspecto exprimido. [...] O aspecto exprimido constituirá agora o 'propósito' do enunciado naquilo somente que ele dividiu, e o encadeamento evocado fará o papel do uso de objetos que ele representará naquilo que o enunciado estudado tem de próprio. (CAREL, 2011, p.220-221, tradução nossa).

Em consonância com Ducrot, quando afirma que o enunciado tem por função ilustrar um retrato da enunciação (DUCROT, 1987), Carel está dizendo que uma frase/enunciado tem por função semântica ilustrar aspectos, concretizando-os (CAREL, 2011). Assim, a TBS marca o movimento semântico do enunciado à frase, ou tecnicamente, a noção de aspecto marca um movimento do sentido (particular, do enunciado) à significação (universal, da frase). Para Carel, o aspecto possui uma característica universal que o determina. Quando Carel, acima, diz que o aspecto "divide algo", ela se refere a uma propriedade universal, assim explicada:

São esses dois valores que refletirão o caráter por sua vez comum e singular de Pedro foi prudente, que refletirão o fato que este enunciado por sua vez divide com João será prudente um Universal e assim se distingue dele por algumas singularidades. O aspecto (PERIGO PORTANTO PRECAUÇÃO) constituirá aquilo que eles dividem. ${ }^{3}$ (CAREL, 2011, p.160, tradução nossa).

\footnotetext{
1 Do original: "Les deux valeurs que la TBS associera à un énoncé seront l'aspect qu'il exprime et l'enchaînement qui le paraphrase.” (CAREL, 2011, p.160).

2 Do original : "Je rends compte de cela en disant que le sens de Pierre a été prudent est double. D'une part, l'énoncé exprime l'aspect argumentatif DANGER DC PRECAUTION et d'autre part il évoque l'enchaînement <c'était dangereux donc Pierre a pris des précautions $>$ [...] L'enchaînement évoqué fait de l'énoncé une formulation concrète de l'aspect exprimé [...] L'aspect exprimé constituera dorenavant le <propos > de l'énoncé en cela seulement qu'il est partagé et l'enchaînement évoqué remplacera le recours à des objets en cela qu'il représentera ce que l'énoncé étudié a de proper." (CAREL, 2011, p.220-221).

3 Do original: "Ce sont ces deux valeurs qui refléteront le caractère à la fois commun et singulier de Pierre a été prudent, qui reflèteront le fait que cet énoncé à la fois partage avec Jean sera prudent un Universel et aussi se
} 
Temos nesses dois trechos-resumo acima, alguns termos técnicos desenvolvidos por Carel para operar o valor do enunciado, que organizamos visualmente deste modo:

Quadro 1 - O valor de uma frase ou enunciado

\begin{tabular}{|l|l|}
\hline \multicolumn{2}{|c|}{ Valor de uma frase ou enunciado } \\
\hline \multicolumn{1}{|c|}{ Aspecto } & \multicolumn{1}{c|}{ Encadeamento } \\
\hline $\begin{array}{l}\text { Expresso pela frase ou enunciação } \\
\text { O propósito da frase ou do enunciado } \\
\text { É universal (divide um universal com outros) }\end{array}$ & $\begin{array}{l}\text { Evocado pelo aspecto (ilustra um aspecto) } \\
\text { Concretiza aspectos (parafraseia aspectos) }\end{array}$ \\
\hline $\begin{array}{l}\text { Exemplo - no enunciado: } \\
\text { Pedro foi prudente. } \\
\text { Temos o aspecto: }\end{array}$ & E temos o encadeamento: \\
PERIGO PORTANTO PRECAUÇÃO & Era perigoso portanto Pedro tomou precauções. \\
\hline
\end{tabular}

Fonte: Elaboração própria.

Operar a linguagem ou discursos pela noção de valor (da frase ou do enunciado) significa que falar em argumentação (significação/sentido) corresponde a pensar no par aspecto e seu encadeamento. Eis o valor: a significação/sentido terá, então, algo de universal (o aspecto) e algo de singular (o encadeamento). O encadeamento particulariza o aspecto, universal. Embora o aspecto seja constituído de um universal, ele é um “mesmo" singularizável pelo encadeamento, já que o encadeamento evocado, por sua vez, varia de um enunciado a outro (CAREL, 2011).

\section{O quadrado argumentativo: a relação aspecto/aspecto}

Para fins de notação teórica, os dois conectores (CONN) bases da TBS são abreviáveis por:

DC (donc do francês) - que quer dizer PORTANTO; e

PT (pourtant do francês) - que quer dizer NO ENTANTO.

Deste modo, para operar as análises manteremos as abreviações DC para movimentos normativos em portanto, e PT para movimentos transgressivos em no entanto. Outras notações necessárias são a já conhecida negação (NEG) e o bloco semântico (BS).

Ainda é relevante frisar que ambos DC e PT são conectores metalinguísticos, noções teóricas, isto é, não se equivalem a procedimentos gramaticais, são conectores técnicos cuja função é operar semanticamente a norma e a transgressão na língua e na

disntingue de lui par quelques singularités. L'aspect (DANGER PT PRECAUTION) constituera ce qu'ils partagent." (CAREL, 2011, p.160). 
enunciação, no sentido que se lhes dá a TBS. E como noção técnica, tanto DC como PT podem facilmente serem substituídos por qualquer conector que carregue a mesma ideia equivalente, como "então, porque, logo, assim, apesar de, porém, contudo etc", que no momento de análise, tornar-se-ão paráfrases de DC ou PT.

Feitas estas pontuações, passemos a aplicá-lo ao quadrado argumentativo, o dispositivo visual das quatro faces integrantes de um bloco semântico:

Figura 1 - $\mathrm{O}$ quadrado argumentativo de:

A

C

[depressa demais CONN risco de sofrer acidente].

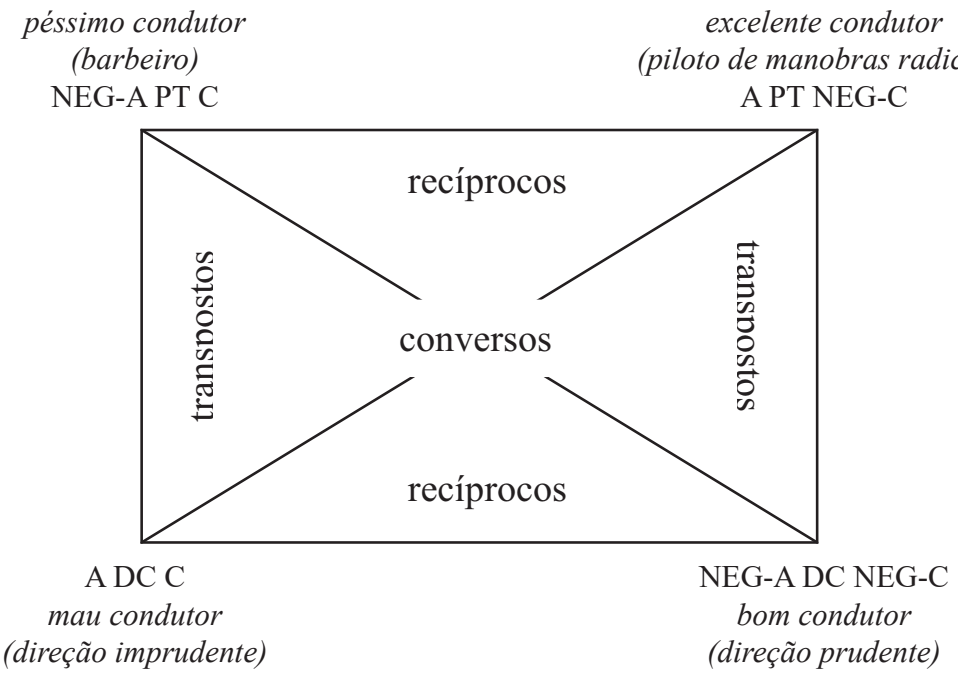

Fonte: Baseado em Ducrot (2009, p.22) e Carel (2011, p.67).

\section{Paradoxo de oposição e paradoxo semântico}

Comecemos por apresentar o que é o paradoxo de oposição, de Carel e Ducrot. Trata-se, aqui, de uma noção técnica, e não subsume ou corresponde ao paradoxo semântico, nosso objeto de estudo.

Falemos primeiro do paradoxo de oposição. Em uma primeira elaboração, os linguistas notam que existe uma relação bloco/bloco (doxal/paradoxal) na significação, isto é, Carel e Ducrot mostraram que para cada bloco doxal (B1) existe um bloco paradoxal (B2). Podemos dispor os dois blocos ladeados:

B1: Pedro está diante do perigo, portanto desistirá (PERIGO DC DESISTIR).

Pedro está diante do perigo, no entanto, não desistirá (PERIGO PT NEG-DESISTIR). 
B2: Pedro está diante do perigo, portanto não desistirá (PERIGO DC NEG-DESISTIR). Pedro está diante do perigo, no entanto desistirá (PERIGO PT DESISTIR).

Reflitamos sobre a estranheza desses dois blocos: numa apreciação mais filosófica ou social - que prefacia a apreciação linguística - observa-se que é mais "óbvio", mais aceito socialmente, que diante do perigo alguém o evite (B1): evitam-se assaltos, ruas perigosas, viagens com altos índices de ocorrências policias, compras em sites suspeitos, etc. Mas não podemos obrigar uma lucidez unilateral universal, e devemos reconhecer que, da mesma maneira, mesmo que menos óbvio ou menos aceito socialmente, há quem goste, aprecie, busque, enfrente, propague e habite com o perigo de toda ordem (B2), como os masoquistas, andarilhos, loucos, revoltados, depressivos etc. Além de uma gama de pensadores que irão afirmar a contra-doxa ao dizer que viver já é estar em perigo, por si só, porque a segurança é imaginária, e o acaso não é previsível.

Focando essas ideias num prisma mais linguístico, mas nem por isso dispensando a reflexão filosófica e social que integra os sentidos, Carel e Ducrot (2008, p.11) propuseram tratar desta relação de sentidos "mais óbvios/menos óbvios" respectivamente como bloco doxal e bloco paradoxal. Assim, nomearam o primeiro bloco (B1: PERIGO DC DESISTIR) de doxal, e o segundo bloco (B2: PERIGO DC NEG-DESISTIR) de paradoxal. A particularidade desta primeira elaboração está no fato de que cada aspecto de B2 é o contrário de cada aspecto de B1. O paradoxo seria um contra-bloco segundo só visível pelo bloco primeiro.

Vejamos agora o paradoxo semântico. Ele consiste em um outro fenômeno, o contrário da oposição: o da nunca divisão. É um método capital que constituirá as análises deste trabalho: a relação interdependente do paradoxo. As significações/ sentidos do paradoxo não são separáveis em partes (não se quisermos manter o paradoxo), e devem ser contemplados na sua estranheza global, interdependente. Por exemplo, os enunciados: "Guerra é paz" e "liberdade é escravidão" (ORWELL, 2014, p.14), de algum modo, devem ser analisados sem o estancamento [guerra] e [paz], por um lado, e [liberdade] e [escravidão], por outro. Nossa metodologia pretenderá uma análise do tipo [guerra+paz] e [liberdade+escravidão]. Isto é o paradoxo semântico.

Tal método é oriundo de duas fontes: os estudos de interdependência de Carel, e a acepção unificadora de Wołowska, quando conclui sobre o paradoxo: "sua função é de unificar, e não de dividir" (WOŁOWSKA, 2008, p.13, tradução nossa) ${ }^{4}$. É um método do "paradoxo do paradoxo": o paradoxo não pode ser resolvido, senão ele não seria um paradoxo. Então, se ele não é solucionável, é apenas observável (observar, para nós, é um gesto analítico de operar na globalidade, sem seccionar). E isto condensa esta metodologia específica longitudinalmente ao longo de todo o trabalho: observaremos o paradoxo, não o resolveremos.

\footnotetext{
Do original: "sa fonction est d'unifier et non de diviser" (WOŁOWSKA, 2008, p.13).
} 
Por fim, convém aqui frisar esta homonímia: uma coisa é o paradoxo de oposiçãonoção teórica inicial de Carel e Ducrot (que se opõe ao senso comum, senso doxal, ou o gradualiza), e outra coisa é o paradoxo semântico - nossa hipótese (que funde significações opostas), e que investigamos aqui. O paradoxo de oposição relaciona doxal/ paradoxal. O paradoxo semântico que nós postulamos impõe uma indissociabilidade, a partir do conceito de interdependência da TBS. Para Carel, a razão de ser de um bloco paradoxal, ao menos nos seus inícios, teoricamente falando, era contrariar (e complementar) aspectos doxais. Para nós, a razão de ser de um paradoxo semântico, teoricamente falando, é estabelecer indissociabilidade entre oposições. Para Carel, o paradoxo é relação (de oposição, em um primeiro momento, e gradação, em um segundo momento). Para nós, o paradoxo semântico é insolucionabilidade e união. Portanto, não queremos equiparar as noções homônimas. Queremos mostrar duas noções distintas: o termo técnico teórico de Carel e Ducrot (paradoxal/doxal), e o nosso, que funde opostos (paradoxo semântico).

\section{Argumentação interna e argumentação externa: a relação presença/ausência da estrutura analisável}

Conforme a TBS, há duas formas de se investigar argumentativamente qualquer palavra: de modo interno e externo a estas palavras. Por exemplo, Carel (2011, p.106) selecionou cinco aspectos que dizem respeito à palavra prudente, dentre outros. São eles: [PERIGO DC PRECAUÇÃO]; [PRUDENTE DC SEGURANÇA]; [PRUDENTE PT NEG-SEGURANÇA]; [RESPONSÁVEL DC PRUDENTE] e [NEG-RESPONSÁVEL PT PRUDENTE]. Carel (2011) vai observar que, na relação com prudente, todos estes aspectos não possuem o mesmo estatuto na sua significação. Ela propõe uma distinção entre argumentação interna e argumentação externa à palavra prudente. Na prática, isso significa que ambas as argumentações (internas e externas) dizem respeito à presença material desta palavra, prudente, no aspecto em foco.

Isso quer dizer que a relação entre a entidade prudente e o aspecto [PRUDENTE DC SEGURANÇA] ilustra a presença desta mesma palavra, possui um estatuto de continuação material "exterior" a essa palavra (prudente dc...), por isso, esse aspecto será dito pertencer à argumentação externa de prudente.

Ao contrário, a relação entre a entidade prudente e o aspecto [PERIGO DC PRECAUÇÃO] ilustra a ausência desta palavra, não contém a presença material da palavra prudente, muito embora a signifique. Este aspecto, segundo Carel, está como que trancafiado no "interior" de prudente, como ela metaforicamente explica, por isso, ele será dito pertencer à argumentação interna de prudente. "O predicado argumentativo ‘tomar-precauções-devido-ao-perigo' é um dos sentidos de prudente" (CAREL, 2011, p.107). Está “dentro", no interior de prudente.

Resumidamente, na relação entre uma palavra e um aspecto, temos dois tipos de argumentações, identificados pelo critério teórico da presença material: 
- Argumentação externa (AE): quando aparece a expressão em foco no aspecto observado. É uma relação de presença com a estrutura analisável. Por exemplo, ao pretender investigar a palavra plena hediondo, iniciando tal investigação pelo aspecto [HEDIONDO DC REPROVAÇÃO JURÍDICA], temos, neste aspecto, uma AE da palavra hediondo. Se tal expressão aparece, intervém materialmente e semanticamente em encadeamentos/aspectos que expõem a expressão (CAREL, 2011), tem-se uma AE;

- Argumentação interna (AI): quando não aparece a expressão em foco no aspecto observado (mas é aspecto dela). É uma relação de ausência com a estrutura analisável. Por exemplo, ao pretender investigar ainda o termo hediondo, mas desta vez observando-o em um dos seus aspectos no qual esta estrutura "hediondo" não aparece, pode-se propor o aspecto: [CHOCANTE DC REPULSIVO]. Neste aspecto, está ilustrada uma AI da palavra hediondo. Fala-se da argumentação que está no interior da estrutura de hediondo. Se tal expressão não intervém materialmente em nenhum dos encadeamentos ou aspectos que descrevem essa expressão (CAREL, 2011), mas intervém ali semanticamente, tem-se uma AI.

É bom marcar que falamos da relação "uma entidade/um aspecto", o que significa dizer que um aspecto em si mesmo não é ele nem uma argumentação externa e nem interna: “um aspecto argumentativo não é em si mesmo 'externo' (ou 'interno'): ele é externo ou interno a tal entidade. Assim, o aspecto [PERIGO DC PRECAUÇÃO] pertence à argumentação interna $(\mathrm{AI})$ de prudente, mas ele pertence à argumentação externa (AE) de perigoso" (CAREL, 2011, p.110, tradução nossa) ${ }^{5}$. E para dar um exemplo, agora paradoxal: assim como o aspecto [NEG-MORTO DC VIVO] pertence, ao mesmo tempo, à $\mathrm{AI}$ do termo saudável e à $\mathrm{AE}$ do termo vivo.

\section{Corpus}

À luz do arcabouço teórico refletido, passemos a um momento menos teóricoexposicional e mais analítico-situacional. Para tal, passemos a apresentar nosso corpus, inicialmente. Trata-se de uma definição de paradoxo do K Dictionaries Password ${ }^{6}$ :

\footnotetext{
Por este trecho, notamos que Carel entende, tecnicamente, que os substantivos e suas adjetivações (perigo, perigoso; prudência, prudente; vida, vivo etc) podem ser observados com equivalência de aspectos, claro que somados às suas caracterizações, operações e singularizações que lhes particularizarão. Por exemplo:

- Pedro está naquele lugar perigoso. Exprime: $\{$ Pedro + lugar + [PERIGO DC EVITAR] $\}$; e

- Pedro está em perigo naquele lugar. Exprime: \{Pedro + [PERIGO DC EVITAR] + lugar\}.

Onde [PERIGO DC EVITAR] é AE de perigo e de perigoso, e é AI de prudência ou de prudente. O encadeamento básico evocado - que poderá ser melhor particularizado, quando enunciado - é:

- Pedro está naquele lugar perigoso, portanto, deve evitá-lo.

- Pedro está em perigo naquele lugar, portanto, deve evitá-lo.

6 Do original : "Paradox ['parədoks] noun a statement etc that seems to contradict itself but which is nevertheless true : If your birthday is on February 29 you could state the paradox that you are thirtheen years old although you have only had three birthdays." (PARKER; STAHEL, 2005, p.374).
} 
Paradoxo ['parədoks] nome. Uma sentença etc que parece contradizer-se a si mesma mas que é verdadeira apesar disso: Se o seu aniversário é em 29 de fevereiro, você poderia professar o paradoxo que lhe atribui treze anos de idade apesar de ter tido apenas três aniversários. (PARKER; STAHEL, 2005, p.374, tradução nossa).

Segundo os locutores deste trecho, teremos, no enunciado inicial, o seguinte encadeamento (o que não significa que o paradoxo seja isso, mas, por uma filiação enunciativa, significa o que este dicionário “diz" ser o paradoxo):

Evoca: Uma sentença parece contradizer-se, no entanto é verdadeira apesar disso. Exprime: [CONTRADIÇÃO PT NEG-FALSA]

No enunciado referido, o aspecto [CONTRADIÇÃO PT NEG-FALSA] pertence à AI de paradoxo, o paradoxo da Lógica (que averigua verdade e falsidade). Por outro lado, se se considerar o elemento anafórico do enunciado, poderíamos reorganizar o aspecto do enunciado:

Evoca: Paradoxo: sentença que parece contradizer-se, no entanto é verdadeira apesar disso.

Exprime: [PARADOXO PT CONTRADIÇÃO VERDADEIRA]

Pelo viés do encadeamento acima, o aspecto [PARADOXO PT CONTRADIÇÃO VERDADEIRA] pertence à AE de paradoxo.

\section{Argumentação externa à direita/argumentação externa à esquerda: a relação entre estrutura analisável e sua presença no suporte ou aporte}

Carel ainda distinguirá na disposição da argumentação externa (AE) de uma entidade, dois outros subtipos de argumentações: a argumentação externa à direita, e a argumentação externa à esquerda. O princípio é o mesmo da argumentação externa: presencial da entidade. Mas agora, presencial-localizacional da entidade. Vejamos.

Tomemos o aspecto [PRUDENTE DC SEGURANÇA] e seu converso [PRUDENTE PT NEG-SEGURANÇA], ambos AE de prudente. Carel (2011) vai explicar que ambos os aspectos pertencem à $\mathrm{AE}$ à direita de prudente, porque o aspecto e os encadeamentos se desenvolvem materialmente à direita de prudente, no seu aporte: [PRUDENTE CONN...].

Do mesmo modo, tomemos o aspecto [RESPONSÁVEL DC PRUDENTE] e seu transposto [NEG-RESPONSÁVEL PT PRUDENTE], ambos AE de prudente. Carel (2011) vai explicar que ambos os aspectos pertencem à $\mathrm{AE}$ à esquerda de prudente, porque o aspecto e os encadeamentos se desenvolvem materialmente à esquerda de prudente, no seu suporte: [... CONN PRUDENTE]. 
Mudemos o eixo analítico para nosso objeto, o paradoxo. Ainda conforme a definição do dicionário acima, vemos que [PARADOXO DC CONTRADIÇÃO VERDADEIRA] é uma $\mathrm{AE}$ à direita de paradoxo. E se analisarmos o segundo enunciado da definição: "Se o seu aniversário é em 29 de fevereiro, você poderia professar o paradoxo que lhe atribui treze anos de idade apesar de ter tido apenas três aniversários", podemos pensar no aspecto ilustrado: [TER 13 ANOS APESAR DE TER 3 ANIVERSÁRIOS DC PARADOXO], que é uma AE à esquerda de paradoxo.

Diante do exposto, ainda é interessante dizer que Carel chamou a atenção para o fato de que Anscombre e Ducrot dedicavam-se e se interessavam apenas por argumentações externas à direita normativas (CAREL, 2011), o que Ducrot assume: "Em 1995, o tipo de argumentação que eu associava a uma expressão estava relacionada com o que chamaríamos agora sua AE em DC." (DUCROT, 2002, p.12). Isso comprova que a TBS veio para aprofundar os estudos da fase anterior, a chamada Argumentação na Língua (ou ANL) de Anscombre e Ducrot, de modo amplo, profundo e rico, até então não desenvolvido, como afirma Ducrot (2006, p.154): “A concepção da semântica linguística na qual eu trabalho atualmente me parece um prolongamento da ANL. [...] Mais precisamente, ela se trata da TBS [...] onde eu vejo um aprofundamento e uma radicalização da ANL." Não se trata de duas teorias, portanto, mas de uma só, aprofundada e radicalizada.

\section{Argumentação estrutural e argumentação contextual}

Nossas abordagens, até então, vão nos conduzindo para nossa questão fulcral: o confronto entre estrutura e seu funcionamento, e a reflexão da significância nesta/ desta relação.

Para apreendermos este quadro, mobilizaremos uma questão que inquieta o semanticista: como estabilizar aspectos em DC e PT diante de estruturas ambíguas? E diante de estruturas que permitem vários usos, e por isso apresentariam vários aspectos? Como estabilizar um método diante desta problemática?

Para tratar este problema, fiel aos pressupostos da antiga ANL, que prevê os trabalhos de semântica determinados pela dupla instância frase/enunciado, Carel vai filiar as noções de AI e AE a outras duas noções: a argumentação estrutural e a argumentação contextual (CAREL, 2011). A condição analítica é a mesma: a argumentação estrutural exprime aspectos inscritos na língua, fora de uso, pura construção do linguista (DUCROT, 1987). Já a argumentação contextual exprime aspectos que dependem da enunciação, do funcionamento da linguagem, da situação, de locutores e interlocutores, do discurso, como bem explicam: “[...] dar o significado de uma expressão é associar-lhe diferentes argumentações que são evocadas por seu emprego." (CAREL; DUCROT, 2008, p.10). Assim, a linguista delimita que um fenômeno linguístico (da língua) será de dimensão frástica (e portanto, expressará argumentações estruturais), e um fenômeno de discurso será de dimensão enunciativa (e portanto expressará argumentações contextuais): 
Eu direi que um aspecto A é estruturalmente expresso por uma entidade linguística E se E exprime A pela sua significação linguística própria; eu direi que A é contextualmente exprimido por E se a associação de E e de A não é linguística (eu me interessarei essencialmente pelo caso em que é o discurso que declara que essa associação é feita). (CAREL, 2011, p.114-115, tradução nossa) ${ }^{7}$.

Podemos pensar esta disposição no quadro geral da TBS:

Quadro 2 - Elaboração da dimensão "língua/fala"

\begin{tabular}{|c|c|}
\hline Língua & Fala \\
\hline Frase & Enunciado \\
\hline Significação & Sentido \\
\hline Argumentação estrutural & Argumentação contextual \\
\hline
\end{tabular}

Fonte: Elaboração própria.

Estamos diante de uma concepção metodológica forte, desde os primórdios da ANL: Anscombre, Ducrot e Carel elegem como foco de atenção analítica o funcionamento da língua para descrever a língua. E esta dupla dimensão, necessária em Semântica, é operada e operável através do enunciado: “[...] eu me interessarei essencialmente pelo caso onde é o discurso que declara que essa associação é feita." (CAREL, 2011, p.115, tradução nossa $)^{8}$. Contudo, ressalta-se, as desenvolturas significantes observáveis na/ através da unidade complexa do enunciado, só são possíveis pelas vias da significação presente na língua, isto é, no léxico, na estrutura.

Vejamos duas aplicações do novo par, argumentação estrutural e argumentação contextual, uma primeira em AE e outra em AI (CAREL, 2011, p.114, tradução nossa) ${ }^{9}$ :

- AE estrutural de rico: [RICO DC TORNAR COISAS POSSÍVEIS] Evocado, por exemplo, na frase: Pedro é rico, portanto, ele pode fazer o que quiser.

- AE contextual de rico: [RICO DC POSSUIR AMIGOS]

Evocado, por exemplo, no enunciado: Pedro é rico, portanto, ele possui muitos amigos.

7 Original: "[...] je dirai qu'un aspect A est structurellement exprimé par une entité linguistique E si E exprime A de par sa signification linguistique même ; je dirai que A est contextuellement exprimé par E si l'association de E et de A n'est pas linguistique (je m 'intéresserai essentiellement aux cas où c'est le discours qui déclare que cette association est faite)." (CAREL, 2011, p.114-115).

8 Original: “Je m'intéresserai essentiellement aux cas òu c'est le discours qui declare que cette association est faite." (CAREL, 2011, p.115).

9 Original: "Pierre est riche, donc il peut faire ce qu'il veut.

Pierre est riche, donc il a beaucoup d'amis." (CAREL, 2011, p.114). 
Segundo Carel, temos na palavra rico uma AE à direita estrutural, já que [RICO DC TORNAR AS COISAS POSSÍVEIS] é própria da significação linguística da palavra rico. "Ter-possibilidades" é uma das significações estruturais da palavra rico. Mas o sentido "a-riqueza-produz-amigos" não está na língua, na estrutura de rico, é uma argumentação contextual. É a enunciação que proporciona este aspecto. Não a estrutura, mas a partir da estrutura. A argumentação contextual é uma associação singular e circunstancial do acontecimento do dizer, produzida a partir da argumentação estrutural. Não há como ser contextual sem passar pelo estrutural, e este é o grande mérito de uma semântica estrutural.

Passemos à aplicação do novo par estrutural/contextual. Para isso, retomemos e dividamos a definição de paradoxo vista acima, em duas partes, cuja análise é:

(A) Uma sentença etc que parece contradizer-se a si mesma mas que é verdadeira apesar disso

Este enunciado acima ilustra três aspectos, no mínimo: dois do tipo AI (um contextual e outro estrutural) e um do tipo AE estrutural. Abaixo, apresentamos pontualmente os três:

- AI Estrutural de paradoxo semântico: [OPOSTOS DC INSEPARÁVEIS]

Evocado, por exemplo, em frases como:

Há duas coisas opostas aqui, e de algum modo, portanto, elas não se separam.

Evocação concretizada, por exemplo, em enunciados como:

Amor é fogo que arde sem se ver; É ferida que dói e não se sente; É um contentamento descontente; $E$ dor que desatina sem doer (CAMÕES, 1975, p.181);

Como vimos, a argumentação estrutural não precisa participar ipsis litteris dos aspectos do enunciado em si. Ela corresponde ao projeto do enunciado de alguma forma. Esta AI estrutural de paradoxo acima foi concretizada da seguinte forma no enunciado (A):

- AI Contextual de paradoxo: [CONTRADIÇÃO PT NEG-FALSA]

Este aspecto pode ser evocado, por exemplo, em enunciados como este logo abaixo: Uma sentença ou etc que parece contradizer-se, no entanto é verdadeira apesar disso. E que foi concretizada, no dicionário em foco, pelo enunciado (A). Concretização esta que por sua vez, surge da AE estrutural de contradição, da Lógica ${ }^{10}$ :

- AE estrutural de contradição lógica: [CONTRADIÇÃO DC FALSA]

10 Quando a Semântica Argumentativa aborda a Lógica em seus trabalhos, parece afastar-se de vertentes da Lógica que convivem bem com a contradição. A abordagem da Lógica que nos interessa aqui, portanto, pode ser explicada pelos estudos do paradoxo realizados por Wołoska $(2008,2005)$. A linguista polonesa evidenciou dois princípios sobre o paradoxo: 
É relevante pontuar que o primeiro enunciado deste dicionário (como todos os dicionários querem) pretende imitar, descrever, explicar uma significação estrutural própria de uma palavra - neste dicionário, a significação (fora de funcionamento) da palavra paradoxo, o que faz valendo-se apenas do saber da Lógica, pelo aspecto estrutural de contradição, enquanto falsidade, deixando muitos aspectos estruturais de outros saberes de fora da definição (deixando, por exemplo, de enunciar o aspecto estrutural acima "opostos-inseparáveis").

É próprio dos dicionários apresentarem definições estruturais segundo a utopia que os constitui, a saber, a de poder converter muitos sentidos de certa palavra em uma única inscrição estrutural. Talvez este seja o maior problema dos dicionários, de um ponto de vista semântico: na tentativa de dizer o estrutural, acabam enunciando o contextual. Ali, toda busca pela significação (geral) termina em sentido (local). Portanto, o dicionário quer operar pela generalização que universaliza, mas sempre o faz pela enunciação que o exclusiviza. Donde vem a máxima: um dicionário pode ser eficiente, mas nunca suficiente.

Observemos o segundo enunciado do dicionário em foco, a definição-exemplo:

(B) Se o seu aniversário é em 29 de fevereiro, você poderia professar o paradoxo que lhe atribui treze anos de idade apesar de ter tido apenas três aniversários

Este enunciado faz ver:

- AI contextual de paradoxo: [29/02 DC 13 ANOS APESAR DE 3 ANIVERSÁRIOS]

Que pode ser evocado, por exemplo, no enunciado:

Ter nascido em 29 de fevereiro significa, portanto, ter 13 anos apesar de ter tido 3 aniversários.

É importante entender o jogo argumentativo do enunciado, que revela que esta AI contextual do paradoxo se forma a partir de duas outras AI:

AI estrutural de 29 de fevereiro: [ÚLTIMO DIA DE UM MÊS DC DATA DE CALENDÁRIO]

AI contextual de 29 defevereiro: [ANO BISSEXTO DC OCORRÊNCIAQUADRIENAL]

> O princípio da Lógica: onde não há lugar para contradição, entendendo a contradição enquanto dois opostos que não se coadunam. Segundo Wołowska (2008, p.31, tradução nossa), “O princípio fundamental da lógica [...] é o princípio da não-contradição."; e

$>$ O princípio da Semântica: onde se aceita sem problemas esta contradição, ainda entendendo a contradição enquanto dois opostos, que agora se coadunam.

É interessante notar que em uma pesquisa recente por nós conduzida, financiada pelo Governo Federal, na França (CAPES PDSE 5637-13-9), observamos em mais de 40 dicionários por toda Europa, América e Japão, em 12 línguas distintas, que muitas definições de "paradoxo" são descritas pela menção desta Lógica (sem especificação) que não suporta a contradição. O que corrobora que esta Lógica, de origem aristotélica e que refuta a contradição nomeando-a de falsa, está longe de estar em desuso. 
É próprio dos dicionários apresentarem exemplos contextuais após uma tentativa de definição estrutural (que por vezes inclusive desconstrói esta própria definição estrutural). Em suma, estes dois enunciados que definem paradoxo acabam por revelar uma das $\mathrm{AE}$ estruturais à direita da própria palavra plena dicionário: [DICIONÁRIO DC DEFINIR PRIMEIRO E EXEMPLIFICAR DEPOIS].

Um outro ponto pode ser produtivo. Os contextualistas de toda ordem e filiação poderiam nos dar réplica enfatizando que a hipótese da argumentação estruturalista subsumi na contextual, já que afirmamos que o simples fato de certa palavra ingressar um dicionário, ser enunciada por locutores autores que escolheram essas palavras para definição, instauram um enunciado histórico, nos dizeres de Ducrot, que não existia antes nem mais existirá depois (DUCROT, 1987). Com o que concordamos, quando dissemos que toda tentativa de dizer o estrutural culmina no contextual.

A questão, contudo, é antes de mais nada, poder pensar na possibilidade e dificuldade de se fazer semântica sem um critério científico basilar: haveria como se pensar no instável (sentido) sem o estável (significação)? Não importa se o segundo é condição necessária para o primeiro, ou se o segundo é uma espécie de volta ao primeiro, ou se um é o futuro do outro, ou seja lá qual for outra definição que se queira dar a esta relação recalcitrante. A TBS entende que a questão é de relação necessária, não de isolamento. Principalmente na cientificidade linguística, esta regularidade parece se impor (mesmo que autores neguem a significação estrutural, interessantemente eles operam redizendo-a de outras formas, acreditando estar erradicando-as), já que para pensar o processo o cientista cria abstrações deste processo, ou como diz Ducrot, o linguista construiu a frase para poder dar conta dos enunciados (DUCROT, 1987). Diríamos em tréplica, e responderíamos no mesmo modelo da réplica: se há na enunciação da significação estrutural contextualidade indesviável, há do mesmo modo, em toda enunciação, significações estruturais insistentes, teimosas, presentes, onipresentes na particularidade de todo enunciado, não ditas mas significadas, significações estruturais que constituem, incomodam, e por isso constroem todo enunciado. De um modo mais refinado, diremos que não há como entender a ideia de movimento sem a ideia de inércia, e isto se aplica em semântica. Não há como entender sentido sem significação, e se há, portanto, funcionamento, é porque existe (e persiste) o que não funciona antes. Toda guerra (sentido) parte da paz (significação). E a paz ecoa no projeto de guerra, mesmo que ela não se efetive e não seja buscada.

Enquanto exemplo concreto, pensemos: seria muito difícil (aliás, seria possível?) explicar que o sentido dos enunciados (A) e (B) acima constroem sua definição de paradoxo sem esbarrar, tocar, remeter, redizer, atualizar, aludir e extrapolar as seguintes significações estruturais que incomodam o funcionamento das palavras destes dois enunciados: 
AI estrutural de paradoxo: [OPOSTOS DC INSEPARÁVEIS];

AE estrutural de contradizer-se: [CONTRADIÇÃO DC FALSA];

AI estrutural de 29 de fevereiro: [ÚLTIMO DIA DE UM MÊS DC DATA DE CALENDÁRIO];

AE estrutural à direita de ter 13 anos: [TER 13 ANOS DC TER FEITO 13 ANIVERSÁRIOS];

AE estrutural à esquerda de aniversário: [AUMENTAR A IDADE DC PASSAR PELO DIA DO ANIVERSÁRIO];

AE estrutural à direita de dicionário: [DICIONÁRIO DC DEFINIR PRIMEIRO E EXEMPLIFICAR DEPOIS].

Dada a riqueza enunciativa, obviamente, além destes aspectos elencados, seria possível ilustrar muitos outros, próprios das significações de todos os termos usados na enunciação das definições (A) e (B).

Pode-se dizer ainda que, de certo modo, um dos sentidos da enunciação de (B) pode ser descrito como tentar "fugir" do estrutural óbvio, de uma condição estrutural da língua (envelhecer significa passar por aniversários), presente na AE estrutural à esquerda de aniversário: [AUMENTAR A IDADE DC PASSAR PELO DIA DO ANIVERSÁRIO]. Mas foge em vão, já que não há como erradicar este aspecto estrutural que "incomoda" o sentido do enunciado todo (envelhecer sem aniversários). O problema não está em [AUMENTAR A IDADE DC VIVER 365 DIAS], nem em [ANIVERSÁRIO DC VIVER MAIS 365 DIAS], mas no aspecto estrutural [AUMENTAR A IDADE DC PASSAR PELO DIA DO ANIVERSÁRIO], que "incomoda" o enunciado acima e o põe em crise semântica.

É justamente o confrontamento significante (o estrutural: envelhecer por aniversários versus o contextual: envelhecer sem aniversários) que produzirá a crise de sentido que acabará por enfatizar, reforçar, voltar, ou no mínimo considerar a AI estrutural de paradoxo: [OPOSTOS DC INSEPARÁVEIS]. É justamente este aspecto estrutural que permite a produção do sentido contextual "estranho" de [alguém-envelhecidosó-com-três-aniversários]. E isso compõe uma de nossas definições formais sobre o paradoxo semântico: a estranheza que funde um aspecto estrutural universal com sua contextualização oposta, inseparáveis entre si.

\section{O complexo argumentativo}

Sobre essa postura insuficiente de estancar a argumentação estrutural ou contextual, duas coisas ao menos há de se ponderar ainda:

I) Como bem disse Ducrot (1987), é a escolha do objetivo do semanticista que elegerá qual argumentação dever-se-á explorar; e

II) O modelo analítico da TBS nunca foi estanque: língua/fala são separadas por más leituras da TBS, do nosso ponto de vista, segundo a leitura que fazemos a partir da 
mobilização do acervo deste saber. Uma teoria que se coloca num lugar de Estruturalismo Enunciativo deve investigar igualmente estas duas palavras (o Estruturalismo e o Enunciativo). Por um lado é indesviável e necessário observar a estrutura lexical, assumindo que "[...] certos predicados argumentativos são lexicalizados, como se eles fossem resumidos pela língua, condensados nas suas palavras." (CAREL, 2011, p.122, tradução nossa) $)^{11}$. Por outro lado, toda estrutura reclama sua finalidade, seu estatuto enunciativo. É por este e neste estatuto enunciativo da estrutura que se flagra como a espessura significante se comporta: “[...] é o discurso que declara que essa associação é feita." (CAREL, 2011, p.115, tradução nossa) ${ }^{12}$.

Sobre este item (II), Carel descreve a dificuldade de um semanticista diante da linguagem, que acaba por proceder a uma espécie de "sentimento intuitivo da língua", um termo geral para dizer que há significações fortes presentes na língua, que parece significar por si só, e irá interferir na enunciação/enunciado: "Para dizer a verdade, eu não vejo como evitar uma recorrência ao sentimento intuitivo da língua [...] o problema prático é saber o que significa esse sentimento intuitivo e como o analisar." (CAREL, 2011, p.121, tradução nossa ${ }^{13}$. É sobre este problema prático que se debruça parte do propósito teórico de nosso trabalho: (tentar) formalizar opacidades significantes/ significáveis.

Uma questão final que parece restar ainda para o semanticista que se vale das noções de AE e AI, contextuais e estruturais, é: existe(m) critério(s) para se estabelecer quantitativamente os aspectos de uma palavra? Isto é, uma palavra comporta quantos aspectos? Ou esta pergunta não caberia para este modelo teórico, já que a ilustração dos aspectos de uma palavra se apresenta de forma livre, pela riqueza de muitos aspectos? Ao falar de Semântica, esta última opção parece ser a resposta mais razoável, já que todo semanticista concorda que a significância, não importa a teoria, é um fenômeno dificilmente explicável ou esgotável por algumas poucas palavras. Por outro lado, a riqueza significante de uma palavra não impede a observação de uma linha de significação central, mais geral. É esta órbita central, geral, universal, que a Semântica Argumentativa quer ilustrar a priori, pelos aspectos de uma palavra.

Deste modo, cada palavra (expressão, frase, texto, imagem etc) terá no mínimo 3 modos de abordar inicialmente o fenômeno da significância: (1) uma AE estrutural à direita; (2) uma AE estrutural à esquerda; e (3) uma AI estrutural. Se for o caso de certa análise de uma palavra em uso, a estas três somar-se-ão os mesmos 3 aspectos, agora contextualmente: (4) uma $\mathrm{AE}$ contextual à direita; (5) uma $\mathrm{AE}$ contextual à esquerda; e (6) uma AI contextual.

11 Original: "[...] certains prédicats argumentatifs sont lexicalisés, comme s'ils étaient résumés par la langue, condensés dans ses mots." (CAREL, 2011, p.122).

12 Original: "C'est le discours qui declare que cette association est faite." (CAREL, 2011, p.115).

13 Original: "À vrai dire, je ne vois pas comment éviter un recours au sentiment intuitif de la langue [...] Le problème pratique est de savoir ce que signifie ce sentiment intuitif et comment l'analyser." (CAREL, 2011, p.121). 
Por exemplo, a palavra plena dicionário pode apresentar, no mínimo, os aspectos:

(1) AE estrutural à direita: [DICIONÁRIO DC EXPLICAÇÃO POR LISTA DE TERMOS];

(2) AE estrutural à esquerda: [ORDENAR O ELENCO DAS SIGNIFICAÇÕES DE UMA LÍNGUA DC DICIONÁRIO];

(3) AI estrutural: [EXPLORAR SIGNIFICAÇÕES DAS PALAVRAS DE UMA LÍNGUA DC APRESENTAR AS SIGNIFICAÇÕES ALFABETICAMENTE]

$\mathrm{Na}$ insuficiência destes 3 aspectos para ilustrar a riqueza da significação de dicionário, o semanticista amplia o leque de aspectos, como por exemplo: [DICIONÁRIO DC LISTA DE TERMOS]; [DICIONÁRIO DC PALAVRAS EM OUTRA LÍNGUA]; [DICIONÁRIO DC INSTRUMENTO LINGUÍSTICO QUE CONSTITUI O SABER DE UMA LÍNGUA] etc. A significação de dicionário é tudo isso e muito mais. É a habilidade do semanticista em flagrar o alcance das significações que norteiam os procedimentos analíticos e seus limites, na Semântica. Contudo, o semanticista elegerá um aspecto chave para os desdobramentos de suas análises (conforme seus objetivos), que pode ser, por exemplo, o número (3) acima.

É este contexto de análise da significação por "família de aspectos" que conduziram Carel e Ducrot (2016), recentemente, à formulação da neonoção de complexo argumentativo. Assim, toda palavra apresenta um complexo de aspectos que a ilustra: “[...] nós chamaremos de 'complexo argumentativo' a um conjunto de esquemas argumentativos." (CAREL; DUCROT, 2016, p.27, tradução nossa) $)^{14}$. Assim, neste artigo trabalhamos o complexo argumentativo de paradoxo e de dicionário. Que em nosso caso específico, se tocam contextualmente e por isso se atravessam semanticamente, devido ao nosso corpus.

\section{Conclusão}

Desse modo, remetemo-nos de algum modo à Benveniste (2006), não porque estejamos assumindo seus pressupostos de semiótica e semântica, mas porque a TBS acaba por concordar com sua ideia base: se se fala em enunciado, sempre é considerável falar em dois planos, um genérico, imanente, fechado nos signos, e outro particular, transcendente, aberto à realidade. Planos estes que se completam e se reclamam, baseado em Saussure, robustecidos pelo trabalho de Benveniste, e cuidadosamente aceitos na TBS, a partir do modo epistêmico de considerar a argumentação por vias semânticas, operável segundo a argumentação estrutural e contextual desta teoria.

14 Original: "On appellera < complexe argumentatif > un assemblage de schémas argumentatifs." (CAREL; DUCROT, 2016, p.27). 
Estamos dizendo que não cremos em uma análise completa, se ela abandona o nível da língua, ou só dela se ocupe. Uso e não uso são duas faces indesviáveis da e para a significação/sentido e suas investigações.

Para nós, a bandeira da uma Linguística sem a língua é pobre e sem raízes, principalmente se se fala em semântica, assim como uma investigação da língua sem o seu uso seria inútil, já que a razão existencial da língua é a enunciação. A sofisticação e a condição do sentido estão na relação língua/fala, seja quais forem os nomes técnicos que recebem. Este artigo, pela reflexão da argumentação estrutural e contextual, evidencia a imensurável riqueza do fenômeno significável da linguagem e ao mesmo tempo sua complexidade, o que mostramos pela Semântica Argumentativa (ou como menciona Ducrot (1987, p. 83), que convenientemente cabe aqui: tratamos de uma teoria de concepção estrutural da enunciação).

Deste modo, cremos ser interessante findar este tópico, talvez polêmico no interior da Linguística pelas infindas filiações que permite, com uma averiguação que nos é interessante porque vem de um analista de discurso, que muito embora se destaque pela ênfase em trabalhos sobre Enunciação, acaba por reconhecer o forte primado da significação estrutural nos estudos enunciativos (tratada por ele de sentido literal):

Se a cada enunciação, algum efeito de sentido pode ser novo e irrepetível, por outro lado, a 'grande massa' dos efeitos de sentido é efetivamente uma retomada de sentidos prévios e com eles coincide. É este o fato que instaura a possibilidade do sentido literal no interior de uma teoria da enunciação. (POSSENTI, 2001, p.30).

\section{Agradecimentos}

FAPEMIG (Processo OET 00514-16) e CAPES - PDSE (Processo 5637/13-9).

MACHADO, J. C. The (insistently) problematization of structural versus contextual for the treatment of significance: an analysis of the 'semantic paradox' by the Theory of Blocks Semantics. Alfa, São Paulo, v.62, n.2, p.277-296, 2018.

- ABSTRACT: this Article shall elect the following key question: how to operate the clash or alliance between language structure and your functioning to reflect the significance in/of this relation? To apprehend this problematic, we will mobilize two objectives, which are issues that disturb the semanticist of any affiliation: how to stabilize, in Linguistic, theoretical aspects before (a) structures out of use, ambiguously semantics, and also before (b) structures that allow multiple uses, and therefore they show / produce various senses? To analyze these goals, we avail ourselves of a definition of "paradox" as corpus, which will allow us to operate, in fact, our object of study: the semantic paradox, neo-notion that observes contraries interdependent, and that we will take as a technique notion within the Theory of Semantic blocks, of Carel and 
Ducrot, basic theoretical affiliation of this research. Our hypothesis coincides with the our results: no matter the strategic procedure that is operating or that is named: the structural signification is way and return point on semantic analysis, which leads us to conclude that if we cannot understand the movement without the idea of inertia, we also cannot work the enunciation sense without structural signification. This condition seems to be imperative in Semantic.

- KEYWORDS: Semantic paradox. Structural argument. Contextual argument.

\section{REFERÊNCIAS}

ANSCOMBRE, J.-C.; DUCROT, O. L'argumentation dans la langue. Bruxelles: Mardaga, 1983.

BENVENISTE, E. Problemas de Lingüística Geral II. Campinas: Pontes, 2006.

CAMÕES, L. V. de. Sonetos. Sintra: Europa-América, 1975.

CAREL, M. Introduction. In: CAREL, M. Argumentation et polyphonie: de SaintAugustin à Robet-Grillet. Paris: Harmattan, 2012. p.7-56.

CAREL, M. L'entrelacement argumentatif: lexique, discours et blocs sémantiques. Paris: Honoré Champion, 2011.

CAREL, M.; DUCROT, O. Langage poétique et discours engagé: cours à École des Hautes Études. France, 2016. Mimeo.

CAREL, M.; DUCROT, O. Descrição argumentativa e descrição polifônica: o caso da negação. Tradução de Leci Borges Barbisan. Letras de Hoje, Porto Alegre, v.43, n.1, p.7-18, 2008.

CAREL, M.; DUCROT, O. La semántica argumentativa: una introducción a la teoría de los bloques semánticos. Buenos Aires: Colihue, 2005.

DUCROT, O. Argumentação retórica e argumentação linguística. Letras de Hoje, Porto Alegre, v.44, p.20-25, 2009.

DUCROT, O. La Sémantique Argumentative peut-elle se réclamer de Saussure? In: SAUSSURE, L. Nouveaux regards sur Saussure: mélanges offerts à René Amacker. Genève: Librairie Droz, 2006. p.153-170.

DUCROT, O. Os intenalizadores. Letras de hoje, Porto Alegre, v.37, p.7-26, 2002.

DUCROT, O. O dizer e o dito. Revisão técnica da tradução: Eduardo Guimarães. Campinas: Pontes, 1987.

ORWEL, G. 1984. Tradução de Alexandre Hubner e Heloisa Jahn. São Paulo: Schwarcz S. A., 2014. 
PARKER, J.; STAHEL, M. K Dictionaries: Password. São Paulo: Martins Fontes, 2005. p.374.

POSSENTI, S. Sobre a leitura: o que diz a Análise do Discurso? In: MARINHO, M. Ler e navegar. Belo Horizonte: Mercado de Letras, 2001. p.19-30.

WOŁOWSKA, K. Le Paradoxe en langue et en discourse. Paris: l'Harmattan, 2008.

WOŁOWSKA, K. Definir le paradoxe: de la logique a la linguistique. Studia Romanica Posnaniensia, Poznań, v.32, p.97-112, 2005. Disponível em: <https:// repozytorium.amu.edu.pl/bitstream/10593/3126/1/10_Katarzyna_Wolowska_Definir le_paradoxe_97-112.PDF $>$. Acesso em: 24 fev. 2015.

Recebido em 18 de maio de 2016

Aprovado em 9 de novembro de 2016 